\title{
Pit-1 binding to specific DNA sites as a monomer or dimer determines gene- specific use of a tyrosine-dependent synergy domain
}

\author{
Jeffrey M. Holloway, ${ }^{1,2}$ Daniel P. Szeto, ${ }^{2,3}$ Kathleen M. Scully, ${ }^{2,3}$ Christopher K. Glass, ${ }^{4}$ and \\ Michael G. Rosenfeld ${ }^{1,2,5}$ \\ ${ }^{1}$ Howard Hughes Medical Institute, ${ }^{2}$ Eukaryotic Regulatory Biology Program, ${ }^{3}$ Biomedical Sciences Graduate Program, \\ ${ }^{4}$ Cellular and Molecular Medicine, University of California, San Diego, School and Department of Medicine, La Jolla, \\ California 92093-0648 USA
}

Transcriptional activation of the prolactin and growth hormone genes, occurring in a cell-specific fashion, requires short-range synergistic interactions between the pituitary-specific POU domain factor Pit-1 and other transcription factors, particularly nuclear receptors. Unexpectedly, we find that these events involve the gene-specific use of alternative Pit-1 synergy domains. Synergistic activation of the prolactin gene by Pit-1 and the estrogen receptor requires a Pit-1 amino-terminal 25 -amino-acid domain that is not required for analogous synergistic activation of the growth hormone promoter. The action of this Pit-1 synergy domain is dependent on the presence of two of three tyrosine residues spaced by 6 amino acids and can be replaced by a comparable tyrosine-dependent trans-activation domain of an unrelated transcription factor (hLEF). The gene-specific utilization of this tyrosine-dependent synergy domain is conferred by specific Pit-1 DNA-binding sites that determine whether Pit-1 binds as a monomer or a dimer. Thus, the critical DNA site in the prolactin enhancer, where this domain is required, binds Pit-1 as a monomer, whereas the Pit-1 sites in the growth hormone gene, which do not utilize this synergy domain, bind Pit-1 as a dimer. The finding that the sequence of specific DNA sites dictates alternative Pit-1 synergy domain utilization based on monomeric or dimeric binding suggests an additional regulatory strategy for differential target gene activation in distinct cell types.

[Key Words: Pit-1; nuclear receptor; transcription; synergy; anterior pituitary]

Received April 26, 1994; revised version accepted June 28, 1995.

The tissue-specific expression of many eukaryotic genes results from combined or synergistic interactions between different classes of transcription factors /e.g., Schüle et al. 1988; Bookbinder et al. 1989; Herbomel 1990; Lin et al. 1990; Baniahmad et al. 1991; Müller et al. 1991; Schaufele et al. 1992; Hershlag and Johnson 1993). The mammalian pituitary gland is a well-characterized model system for investigating the molecular mechanisms responsible for the cell type-specific activation of gene expression and proliferation that define distinct cell phenotypes within an organ ( $\mathrm{Li}$ et al. 1990; Lin et al. 1992; Godfrey et al. 1993; Lin et al. 1993; Rhodes et al. 1993; Andersen and Rosenfeld 1994). While the pituitary-specific transcription factor, Pit-1, is required for activation of both the prolactin gene in lactotrophs and the growth hormone gene in somatotrophs, a combinatorial code involving additional transcription factors

${ }^{5}$ Corresponding author. must underlie their cell-specific and distinct temporal patterns of expression. In the case of the prolactin gene, both the promoter and a distal enhancer located $1.5 \mathrm{~kb}$ upstream of the transcription initiation site can confer Pit-1-dependent cell-specific activation in cell culture (Nelson et al. 1986; Gutierrez-Hartman et al. 1987; Cao et al 1988; Nelson et al. 1988; Day and Maurer 1989; Kim et al. 1989). However, the distal enhancer confers $\sim 95 \%$ of observed levels of prolactin gene expression in cell culture, and synergistic interactions between the prolactin promoter and distal enhancer region are required to achieve effective physiological levels of gene expression during normal development /Crenshaw et al. 1989|. Several lines of evidence suggest that Pit-1 alone is ineffective in activating the prolactin gene distal enhancer (Mangalam et al. 1989; Simmons et al. 1990). Ligand-bound estrogen receptor synergizes with Pit-1 to permit activation of the distal enhancer/Slabaugh et al. 1982; Crenshaw et al. 1989; Day et al. 1990; Simmons et al. 1990). In the case of the growth hormone gene, Pit-1 
can synergize with either $\mathrm{Zn-15}$ or thyroid hormone $\left(\mathrm{T}_{3}\right)$ receptor in activation of the growth hormone promoter (e.g., Schaufele 1992; Lipkin et al. 1993; Lira et al. 1993).

Pit-1 has generally been found to bind as a dimer to cognate recognition elements in distal target genes. These elements generally consist of a core motif of consensus sequence, A/TTATNCAT, preceded by an adjacent A/T-rich sequence. One molecule of the Pit-1 dimer binds to the TATNCAT sequence, whereas the second molecule binds to the preceding A/T-rich motif (Ingraham et al. 1990). The precise sequence of the preceding A/T-rich motif varies widely among naturally occurring Pit-1-binding sites, raising the possibility that these sequence differences could direct the binding of Pit-1 molecules in distinct conformations.

In this paper we define a 25 -amino-acid region within the amino terminus of Pit-1 that is necessary for the short-range synergistic interaction between Pit-1 and the estrogen receptor that is involved in transcriptional activation of the prolactin gene. Surprisingly, function of this Pit-1 synergy domain is not required for comparable synergistic events in the growth hormone promoter. Several lines of evidence suggest that the gene-specific use of this synergy domain is dictated by the differential binding of Pit-1 to the critical regulatory elements within the prolactin and growth hormone genes as a monomer or dimer, respectively. The observation that distinct synergy domains of a single transcription factor are utilized in a gene-specific manner based on the sequence of its DNA-binding sites has intriguing implications for control of cell type-specific patterns of gene expression.

\section{Results}

DNA elements required for synergistic activation of the prolactin enhancer

The distal enhancer of the rat prolactin gene contributes $90 \%-99 \%$ of prolactin gene activation both in cultured pituitary cell lines and in vivo (Nelson et al. 1988; Crenshaw et al. 1989). In heterologous cells, Pit-1 has minimal effect on the distal enhancer function unless activated estrogen receptor is also present (Fig. 1A). The estrogen response element (ERE) is a 24-bp element $(-1583$ to -1561$)$ that contains an imperfect palindromic core binding motif spaced by 3 bp (Maurer and Notides 1987; Waterman et al. 1988). Mutation of this response element to a sequence that does not bind estrogen receptor abolished synergistic trans-activation by Pit-1 and estrogen receptor (Fig. 1A). Tamoxifen, an estrogen antagonist that does not alter DNA binding by estrogen receptor, did not elicit a synergistic response between estrogen receptor and Pit-1 (data not shown). Estrogen receptor and Pit-1 mutants that were incapable of binding to DNA no longer exhibited synergism, indicating that DNA binding by each factor was required for synergy (data not shown).

To investigate whether specific Pit-l sites were required for the synergistic interactions between Pit-1 and the estrogen receptor, each Pit-1 element in the distal enhancer (1D, 2D, 3D, and 4D) was mutated individually. Whereas mutation of individual Pit-1-binding elements 2D, 3D, and 4D did not prevent synergism, mutation of the Pit-1-binding element 1D, located directly adjacent to the ERE, abolished synergism between the estrogen receptor and Pit-1 (Fig. 1B). Mutation of all four Pit-1 binding sites in the prolactin promoter to nonbinding sites (P4600) did not affect Pit-1/estrogen receptor synergistic responses (data not shown). The overall activation of this reporter was quite low, however, because of the well-described synergy between the distal enhancer and promoter (Crenshaw et al. 1989; Day and Maurer 1989; Simmons et al. 1990; Nowakowski and Maurer 1994). The sequence between -1600 and -1539 , encompassing the 1D Pit-1 site and the adjacent ERE (1D-ERE), was transferred 5' of a prolactin promoter in which all four Pit-1-binding elements had been mutated into nonbinding sequences (Fig. $1 \mathrm{C}$ ), and to a minimal prolactin promoter (Fig. 1D). Whereas both Pit-1 and estrogen receptor were capable of minimal activation in both contexts, together they exerted a synergistic effect on reporter gene expression that was dependent on the -1600 to -1539 sequence (Fig. 1C,D). An identical element containing a 6-, 7-, or 10-bp insert interposed between the Pit-1-binding site and the ERE conferred synergism similar to that conferred by the wild-type element (Fig. 1D; data not shown), suggesting that the transcriptional synergy did not require a precise spacing or helical placement of Pit-1 and estrogen receptor DNAbinding sites. Synergy was no longer observed, however, with spacing of $54 \mathrm{bp}$ between these DNA response elements indicating that proximity of these elements was a requirement for synergy (Fig. 1D). Placement of the 1DERE element adjacent to both the SV40 and thymidine kinase promoters produced comparable synergism between Pit-1 and estrogen receptor (data not shown). Collectively, these data indicate that the -1600 to -1539 sequence is both required for synergy and sufficient to transfer synergistic activation to different promoter contexts.

\section{Pit-1 and the estrogen receptor do not exhibit direct cooperative binding to the prolactin gene enhancer}

Having established the DNA sequence required for synergy, we next determined whether direct cooperative DNA-binding interactions occurred on this site, based on the observation that both the Pit-1 and the estrogen receptor-binding sites were relatively low affinity sites. Avidin-biotin complex DNA (ABCD) (Glass et al. 1988)binding assays that quantitate the amount of Pit-1 protein bound to a biotinylated 1D-ERE element in the absence and presence of baculovirus-produced estrogen receptor protein revealed no effect of estrogen receptor on Pit-1 binding (Fig. 2A). Similarly, binding of estrogen receptor to 1D-ERE was not increased in the presence of either bacterially expressed or in vitro-translated Pit-1 (Fig. 2A). Electrophoretic mobility shift analyses and offrate experiments also failed to detect cooperative DNA 
Holloway et al.

Figure 1. Synergistic interactions between Pit-1 and estrogen receptor are required for activation of the prolactin gene distal enhancer. $(A)$ Cotransfection assays in CV-1 cells utilizing Pit-1 and/or estrogen receptor expression plasmids to determine activation by Pit-1, estrogen receptor, or by both proteins of the prolactin promoter, enhancer/promoter, or an enhancer/promoter in which the ERE has been mutated (ERE-Mut) to abolish estrogen receptor binding as described in Materials and methods. $(B)$ Analysis of prolactin gene regulation using reporter plasmids in which the Pit-1 sites in the prolactin enhancer were individually mutated (IDMut, 2D-Mut, 3D-Mut, 4D-Mut). The mutated prolactin reporter genes were cotransfected with Pit-1 alone, or with both Pit-1 and estrogen receptor. All data were confirmed in at least four independent experiments. $(C)$ The ability of Pit- 1 and estrogen receptor to transfer synergy on the ID-ERE to a prolactin promoter that lacked Pit-1-binding sites. The reporter contained the prolactin enhancer 1D-ERE region from -1600 to -1539 bp fused to the mutated $\mathrm{P} 460 \Delta$ prolactin promoter. $(D)$ The ability of Pit- 1 and estrogen receptor to transfer synergy to a minimal prolactin promoter containing wild-type ID-ERE, IDERE with 6 bp inserted between the lDPit- 1 site and the ERE, and 1D-ERE with 54 bp inserted. Similar results were obtained in five different experiments. No effects were observed in response to Pit-1 or estrogen in the absence of the 1D-ERE region.
A

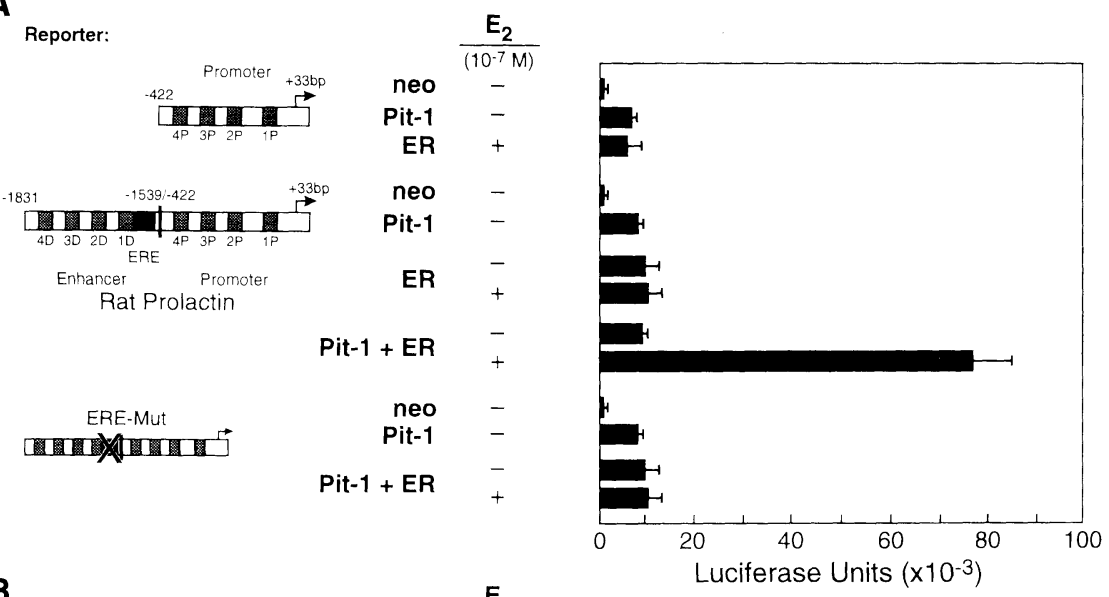

B
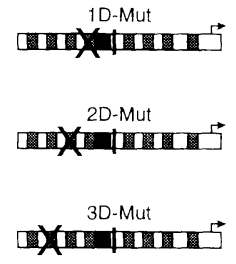

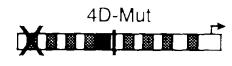

C

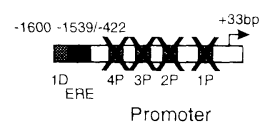

D

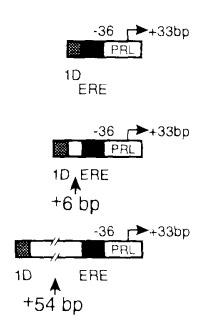

binding between Pit-1 and estrogen receptor on the prolactin 1D-ERE site (data not shown).

Assessment of cooperative DNA-binding interactions between Pit-1 and estrogen receptor on low affinity sites in vivo was investigated by experiments in which the prolactin ERE was mutated to the vitellogenin ERE (VitERE), which exhibits $\sim 10$ - to 50-fold higher affinity for estrogen receptor. Whereas the Vit-ERE in the context of the prolactin enhancer was capable of minimally responding to estrogen in the absence of Pit-1 (Fig. 2B),
Pit- 1 and estrogen receptor synergy was equivalent to or greater than that observed with the wild-type distal enhancer (Fig. 2B). Therefore, the low affinity estrogen site was not a prerequisite for synergy. Conversely, replacement of the Pit-1 prolactin 1D element with a LexAbinding element also exhibited synergy between the estrogen receptor and a hybrid protein containing the amino terminus of Pit-1 fused to the LexA DNA-binding domain (see Fig. 4B). Despite the lack of detectable DNA-dependent cooperative binding interactions, we 
A
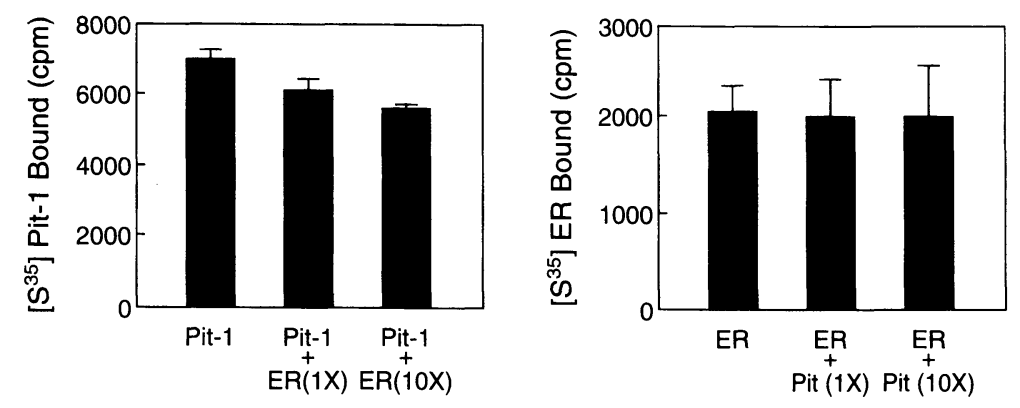

B
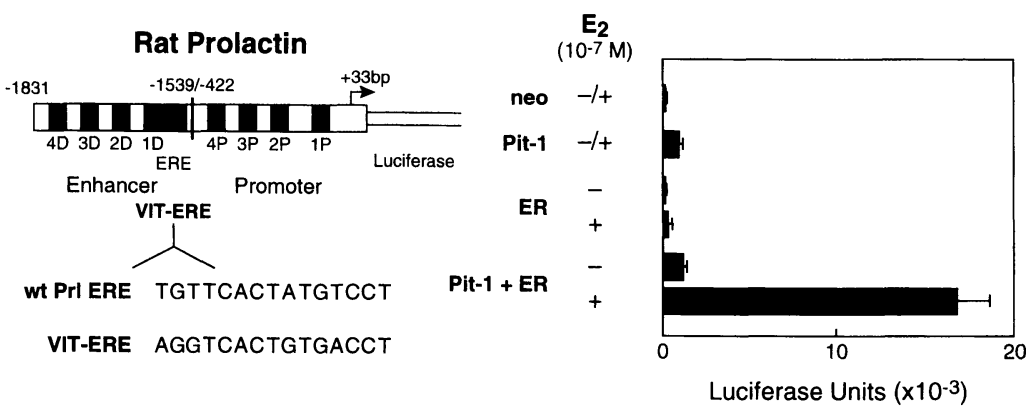

Figure 2. Transcriptional synergism between Pit- 1 and estrogen receptor does not involve direct cooperative DNA binding. $(A) \mathrm{ABCD}$ binding of radiolabeled in vitro-translated Pit-1 (left) or ER (right) to a biotinylated ID-ERE prolactin element ( -1600 to $-1539 \mathrm{bp}$ ) in the absence or presence of baculovirus-produced estrogen receptor or bacterially produced Pit-1. Similar results were obtained in four independent experiments. $(B)$ Cotransfection of the mutated prolactin enhancer/promoter Vit-ERE with Pit-1, estrogen receptor, or both transcription factors together was performed to determine whether synergism occurs when estrogen receptor has an increased binding affinity for its element. The data for neo and Pit- 1 alone was identical in the absence $(-)$ or presence $(+)$ of estrogen. The mutant Vit-ERE reporter replaced the first two half-sites of the prolactin ERE with the palindromic Vit-ERE. Similar results were obtained in four additional experiments. also examined direct protein-protein interaction as a possible mechanism for the synergistic actions of Pit-1 and estrogen receptor. Using either glutathionine $S$-transferase (GST) precipitation assays or coimmunoprecipitation assays, we detected a weak protein-protein interaction between Pit-l and estrogen receptor, primarily involving the DNA-binding domains of each protein, consistent with other reports of interactions between these proteins (Nowakowski et al. 1994). These interactions do not involve the amino terminus of Pit-1 and are not required for synergy based on the LexA-Pit-1 fusion protein function. These results are also consistent with the observation that a specific spatial relationship between Pit-1 and estrogen receptor-binding sites was not required for synergy. Thus, while cooperative DNA binding may account for some cases of synergy, synergistic interactions between Pit- 1 and the estrogen receptor appear to be representative of the growing number of examples where mechanisms other than direct cooperative binding underlie synergistic gene activation (e.g., Carey et al. 1990; Lin et al. 1990; Martinez et al. 1991; Peterson and Herskowitz 1992).

\section{Specific trans-activation domains of Pit-1 and the estrogen receptor are required for synergism}

Mutant estrogen receptors were used to test whether either of the two distinct estrogen receptor trans-activation domains, the amino-terminal Taf-1 or the carboxyterminal Taf-2 sequences (Kumar et al. 1987; Lees et al. 1989; Tora et al. 1989; Tasset et al. 1990), were critical for synergism. To preserve ligand-dependent DNA binding by the estrogen receptor, we utilized a mutant containing amino acid changes within the extreme carboxy-terminal Taf- 2 region of the estrogen receptor that permitted ligand binding but abolished basal estrogenstimulated trans-activation function (Lees et al. 1989; Fawell et al. 1990; Tzukerman et al. 1994). This mutant receptor is incapable of binding the $140-$ and $160-\mathrm{kD}$ proteins that have been postulated to function as coactivators (Halachmi et al. 1994). We therefore evaluated one such mutation (ERMutTaf2) (Tzukerman et al. 1994), that fails to trans-activate on binding to the Vit-ERE (Tzukerman et al. 1994; data not shown). Intriguingly, this mutant receptor was $\sim 30 \%$ impaired in synergistic transcriptional activation with Pit-1 (Fig. 3A). A second mutant estrogen receptor lacking the amino-terminal Taf-1 (ER $\Delta$ Taf-1) domain was $\sim 60 \%$ impaired in synergistic actions with Pit-1. With mutation of both Taf-1 and Taf-2 domains, synergy was entirely abolished (Fig. 3A).

Deletion of the amino-terminal trans-activation domains of Pit-1 (residues 8-128) essentially abolished its ability to trans-activate the prolactin promoter and abolished synergy with the estrogen receptor (Fig. 3B). Use of an alternative initiator methionine at residue 26 that generates the $31-\mathrm{kD}$ form of Pit-1 (Voss et al. 1991) did not significantly alter synergy, indicating that the initial 26 amino acids were not critical for synergy function.

\section{The Pit-1 amino-terminal trans-activation domain selectively transfers synergy to a heterologous DNA-binding domain}

Based on the requirement of the amino-terminal transactivation domains of Pit-1 for synergy with the estrogen 


\section{A}

Figure 3. Estrogen receptor and Pit-1 trans-activation domain requirements for synergistic activation of the prolactin gene. (A) Mutant estrogen receptors altered in the carboxy-terminal trans-activation domain (MutTaf2), lacking the amino-terminal trans-activation domain ( $\Delta$ Taf 1$)$, or containing both

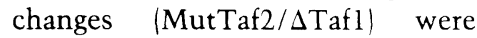
cotransfected with Pit-1 and a prolactin enhancer/promoter luciferase reporter plasmid. All data were obtained in the presence of $10^{-7} \mathrm{M}$ estrogen. Data are presented as luciferase light units. For Pit-1 and estrogen receptor alone, the data are identical in the absence or presence of estrogen. (B) Wild-type (WT) or deleted Pit-1 proteins lacking amino acids 8-128 $(\Delta 8-128)$ or the first 26 amino acids $(\Delta 1-26)$ were cotransfected with estrogen receptor and the prolactin enhancer/promoter reporter plasmid. All data were obtained in the presence of $10^{-7} \mathrm{M}$ estrogen. Data are presented as luciferase light units.

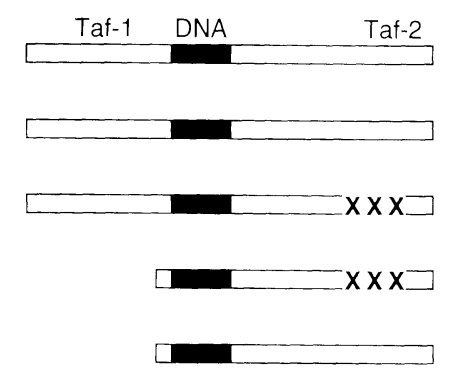

\section{$B$}

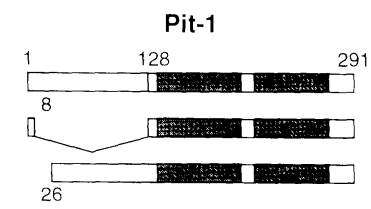

Rat Prolactin
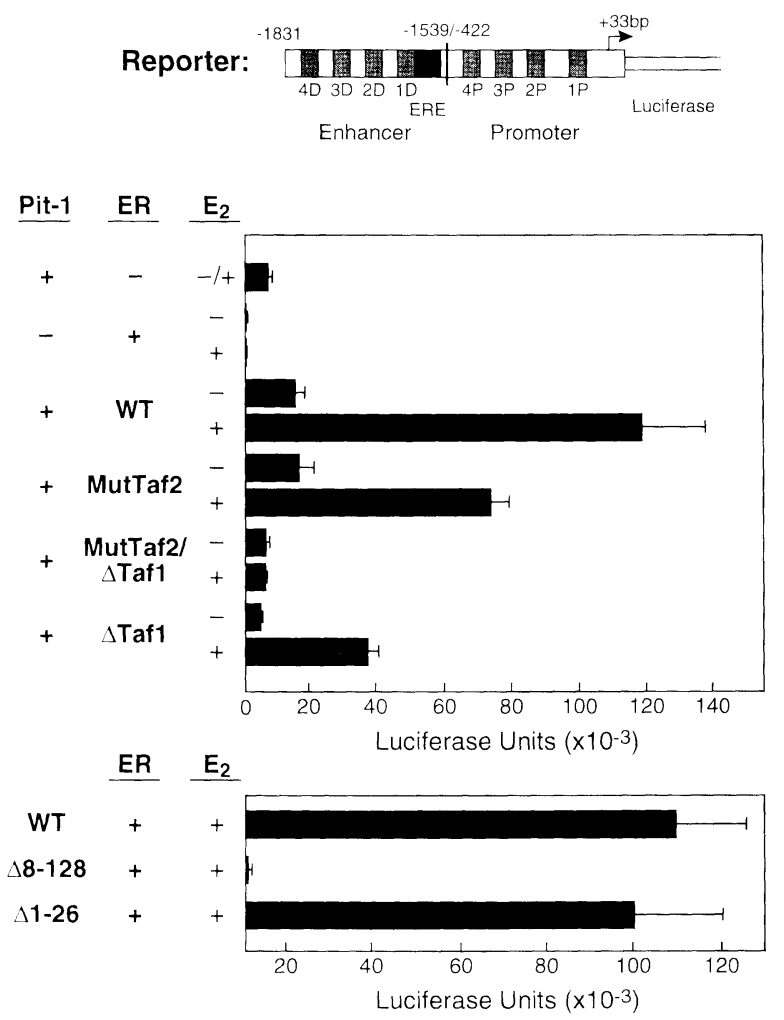

receptor, a domain transfer experiment was performed. Chimeric proteins containing the LexA DNA-binding domain (amino acids 1-87) fused to the trans-activation domains of VP16, Sp1, Oct-2, and Pit-1 transcription factors were evaluated for their ability to trans-activate a minimal prolactin promoter containing two copies of a LexA DNA response element (Fig. 4A). All four transactivation domains were functional in the context of LexA fusion proteins, with VP16 and Spl domains conferring higher levels of trans-activation than either Oct-2 or Pit-1 domain proteins (Fig. 4A). These proteins were then tested for their ability to synergize with estrogen receptor on promoters that contained a single palindromic LexA response element and the prolactin ERE (Lex/ ERE). In the case of the VP16, Sp1, and Oct-2 fusion proteins, transcriptional responses in the presence of liganded estrogen receptor on this element (Fig. 4B) were generally close to additive, which is consistent with previous reports of synergy between a variety of transcription factors in specific promoter contexts (e.g., Schüle et al. 1988; Strähle et al. 1988; Lin et al. 1990). The LexAPit-1 fusion protein invariably exhibited synergistic stimulation with estrogen receptor that was higher (twoto fivefold) than the multiplied effect of each factor alone. All fusion proteins bound essentially equally to the LexA DNA site in the presence or absence of estrogen receptor (data not shown). These data suggest that the Pit-1 amino-terminal trans-activation domain is particularly effective in synergizing with the estrogen receptor and functions within the context of a heterologous DNA-binding domain, prompting a more detailed definition of the Pit-1 sequences that confer synergistic gene activation.

\section{Definition of the Pit-1 synergy domains}

We have demonstrated previously that the amino-terminal 80 amino acids of Pit- 1 serve the major trans-activation function on both prolactin and growth hormone gene promoters and that residues $1-40$ and $40-80$ can independently transfer trans-activation function to the LexA DNA-binding domain (Ingraham et al. 1990). Two exons are represented in this amino-terminal trans-activation region: amino acids $1-47$ are encoded by exon 1 , and amino acids 48-72 are encoded by exon 2 of the pit-1 gene. The actions of each exon-encoded trans-activation domain (amino acids 1-47, 48-72) were initially evaluated with respect to both basal prolactin gene activation and synergistic interactions with the estrogen receptor. In these experiments we chose to truncate the exon 1-encoding region at residue $44(\Delta 1-44)$ to evaluate exon 1 function and to delete residues $45-72$ to evaluate exon 2 function $(\Delta 45-72)$. As shown in Figure 5A, deletion of exon 1-encoded information (residues 1-44), produced only a minimal loss of basal trans-activation and a $50 \%-$ $60 \%$ decrease in synergism with the estrogen receptor. Deletion of the exon 2-encoded domain of Pit- 1 also produced a minimal loss of basal transcription function. In contrast, this deletion entirely abolished synergy with the estrogen receptor in the context of the prolactin gene (Fig. 5A). Comparable data were obtained with precise deletion of the exon 2-encoded residues 48-72/data not 
A

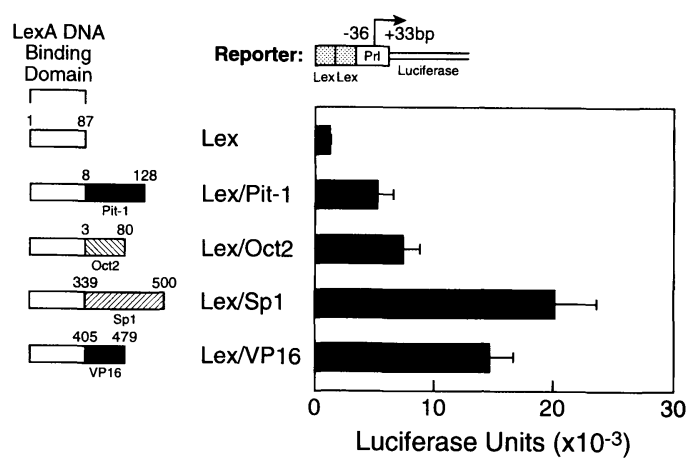

B

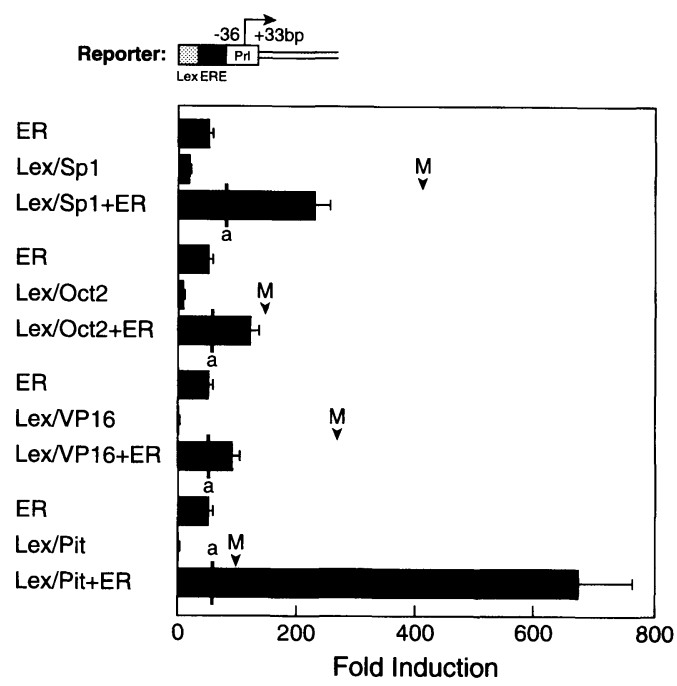

Figure 4. The Pit-1 amino terminus transfers synergistic interaction with the estrogen receptor to a heterologous DNA binding domain. $(A)$ The DNA-binding domain (amino acids 1-87) of the Escherichia coli transcription factor LexA was fused to the activation domains of four factors known to positively activate transcription. These domains include the amino terminus of Pit-1 (Lex/Pit), the Oct-2 trans-activation domain (Lex/Oct), the Spl B trans-activation domain (Lex/Spl), and a portion of the VP16 acidic trans-activation domain (Lex/VP16). These Lex fusion proteins were analyzed in cotransfection assays for their ability to trans-activate a reporter containing two copies of a palindromic Lex DNA-binding element fused to the minimal prolactin promoter $(-36$ to $+33 \mathrm{bp})$. $(B)$ Comparison of induction of a Lex-ERE-P-36 reporter plasmid by the Lex fusion proteins, estrogen receptor, or both proteins together. Data are presented as fold induction. All data were obtained in the presence of $10^{-7} \mathrm{M}$ estrogen. (a) Fold induction expected if proteins gave additive induction; $(\mathrm{M})$ fold induction expected if proteins gave multiplicative induction. Similar results were obtained in five independent experiments.

shown). As a further control, deletion of exon 3-encoded residues, 73-128, which actually increased Pit-1 activation of the prolactin promoter two- to threefold, resulted in identical fold effects on synergy as wild-type Pit-1 (Fig. 5A). Western blot analysis using Pit- 1 antisera and electrophoretic gel mobility shift analysis of nuclear extracts from cells transfected with each mutant detected ap- proximately equivalent amounts of Pit-1 protein, with levels differing in separate experiments by less than twofold (Fig. 5A,B, insets). Therefore, for synergistic activation of the prolactin gene by Pit-l and the estrogen receptor, a single exon-encoded Pit-1 trans-activation domain appears to be particularly important.

We therefore investigated the exon 2-encoded sequence of Pit-1 (residues 48-72) at a higher level of resolution by generating a series of amino acid mutations. This region contains 3 tyrosine residues at positions 53 , 60 , and 67 , and multiple serine, proline, and glycine residues (Fig. 5B). Analysis of predicted secondary structure characteristics (Garnier 1978), and computer-based comparison of short sequences of the Pit-1 amino-terminal trans-activation domain to regions of proteins for which structure has been solved by X-ray crystallography failed to identify any obvious structural motif for the exon 2 -encoded region (amino acids 48-72). Generating a panel of single amino acid mutations spanning the entire 25 residues of the exon 2 sequence revealed that no one mutation significantly altered either basal or synergistic activation functions (data not shown). Therefore, a series of dual amino acid mutations were prepared and evaluated. Most Pit-1 proteins harboring a double mutation exhibited virtually wild-type funtion (see examples, Fig. 5). Surprisingly, when any two of the three tyrosine residues were mutated, the ability of Pit-1 to synergize with the estrogen receptor was abolished, while the basal trans-activation function of Pit-1 was preserved (Fig. 5B). In these experiments, mutant Pit-1 proteins were expressed at levels comparable to wild-type Pit-1 (Fig. 5B; data not shown). To evaluate whether either position or spacing of the tyrosine residues was critical for synergy function, second-site amino acid mutations were made, in the context of amino acid substitutions, that resulted in relocating the tyrosine at position 60 to either position 61 or 63 (Fig. 5B). Both of these mutant Pit-1 proteins, and a single mutation of tyrosine- 60 to alanine, retained full capacity for basal trans-activation and for synergistic activation with estrogen receptor (Fig. 5B). In contrast to the double tyrosine substitutions, mutations of other pairs of amino acids between the tyrosine residues resulted in no impairment of synergistic function. These observations serve to delineate a distinct domain in Pit-1 that is absolutely required for synergy, but not for basal trans-activation function.

Based on the requirement of tyrosine residues for effective function, it was of interest to determine whether tyrosine-containing trans-activation domains within other transcription factors could functionally substitute for the Pit-1 synergy domain. Recently, the lymphoidspecific transcription factor (hLEF) (Waterman and Jones 1990; Travi et al. 1991; Waterman et al. 1991; Giese and Grosschedl 1993; van Genderson et al. 1994) was found to possess an 80-amino-acid trans-activation domain. Characterization of this domain revealed a 13-aminoacid sequence containing 3 tyrosine residues, each spaced by 5 residues, that exerted functional consequences when mutated (Carlsson et al. 1993). Therefore, this 13-amino-acid sequence (residue 102-114 of hLEF-1) 
A

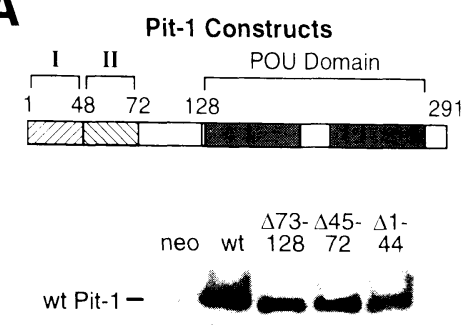

B

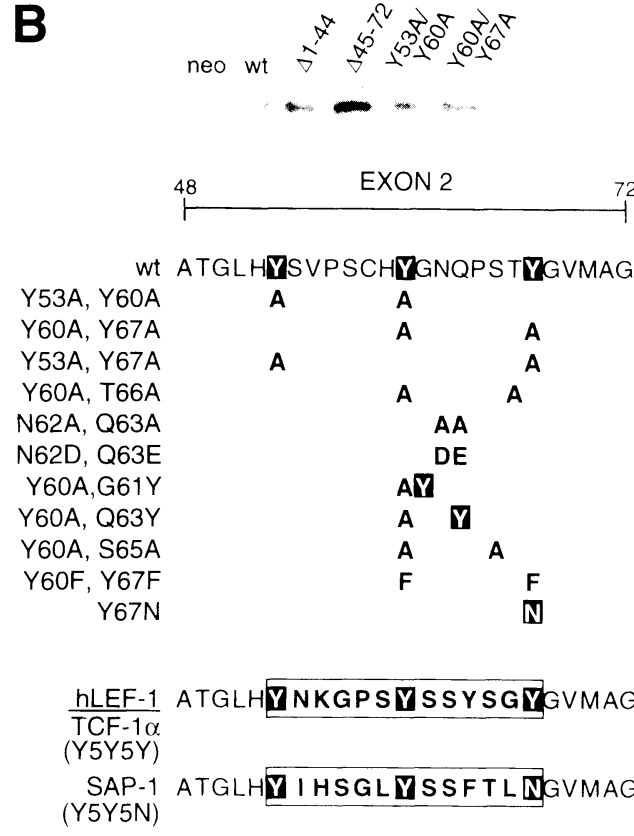

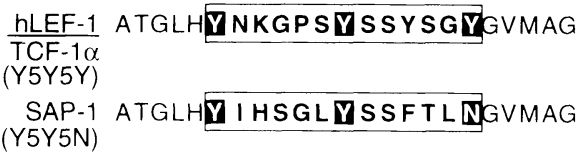

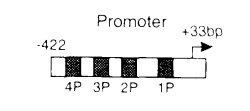

Basal Activation (\% wt)

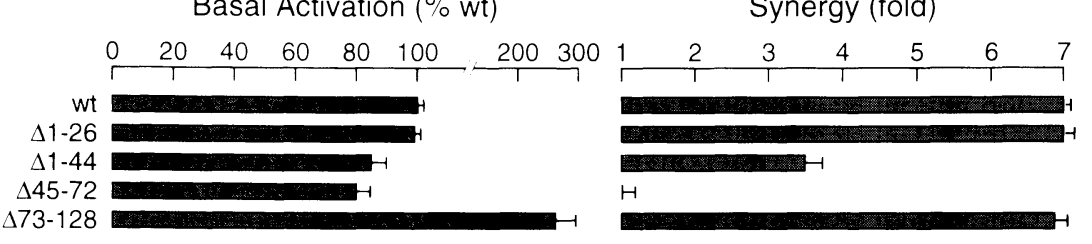

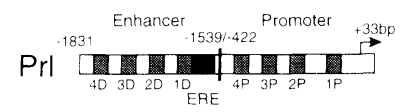

Synergy (fold)
Basal Activation (\% wt)

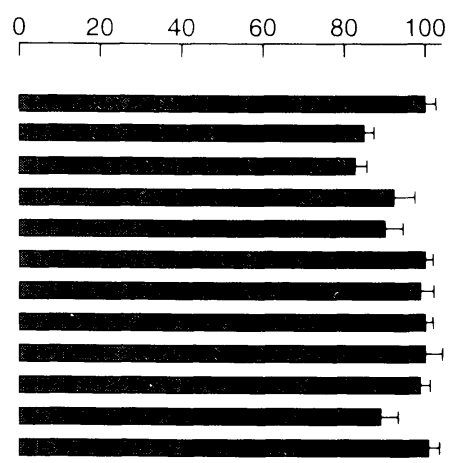

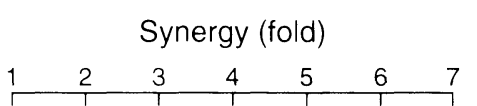

Figure 5. Two of three tyrosine residues encoded by exon 2 of pit-1 are absolutely required for synergism with estrogen receptor in activation of the prolactin gene enhancer. $(A)$ Cotransfection of Pit-l deletion mutants $(\Delta 1-26, \Delta 1-44, \Delta 45-72$, and $\Delta 72-128)$ with estrogen receptor and prolactin promoter or enhancer/promoter reporter plasmids. Data are expressed as a percentage of wild-type Pit-1 activity for basal activation of the prolactin promoter, and as fold synergy with estrogen receptor in activation of the enhancer/ promoter. Nuclear extracts from transfected cells were analyzed for Pit-1 protein levels using specific antisera following separation on SDS/PAGE and transfer to nitrocellulose membranes. The migration of bacterially expressed holoprotein (wt Pit-1) is noted by the bar. $(B)$ Precise spacing between critical tyrosine residues in exon 2 is not required for synergism. Cotransfection of Pit-1 double amino acid mutants with estrogen receptor to analyze the role of the spacing and the phosphorylation of tyrosine residues in both basal and synergistic trans-activation function (Y53A/Y60A, Y60A/Y67A, Y53A/Y67A, Y60A/T66A, N62A/Q63A, N62D/Q63E, Y60A/G61Y, Y60A/Q63Y, Y60A/G61A, Y60F/Y67F, and Y67N). Two other mutations substitute either a region of human LEF-1 (hLEF-1) amino acids 102-118 (Y5Y5Y) or a comparable region of SAP-1 (Y5Y5N), involved in interactions with SRF, for residues 53-67 of Pit-1 (Y6Y6Y). Nuclear extracts from transfected cells were analyzed for Pit-1 DNA binding utiizing mobility gel shift assays (see Materials and methods) shown in the inset. Effects were reproduced in a minimum of three independent experiments.

was substituted for residues $53-67$ of Pit-1. This substitution altered the Pit-1 sequence spacing Y6Y6Y to a spacing of Y5Y5Y, with no other obvious homology in the intervening residues (Fig. 5B). Remarkably, basal activation and synergy function with estrogen receptor were fully maintained. The Y5Y5Y region of hLEF-1 was also noted by Carlsson et al. (1993) to be similar to sequences in the Ets-related factors SAP-1 and Elk-1, which mediate binding to the serum response factor (SRF) (Dalton and Treisman 1992; Treisman et al. 1992; Carlsson et al. 1993). The region from SAP-1 that mediates SRF binding was also substituted for residues 53-67 of Pit-1 and tested for synergy function. In contrast to the results obtained with the hLEF-1 transfer, the Y5Y $5 \mathrm{~N}$ sequence of SAP-1 was not able to substitute for the Y6Y6Y region of Pit-1 in synergy with estrogen receptor (Fig. 5B). Because SAP-1 contains a Y5Y5N sequence instead of a Y5Y5Y, tyrosine-67 of Pit-1 was changed to asparagine (Y6Y6N). This protein retained full synergy function with estrogen receptor. These data indicate that the tyrosine residues are a critical component of the domain required for synergistic activation of the prolactin gene with the estrogen receptor, but other aspects of the amino acid sequence and structure must also be necessary for synergistic function. One possible explanation is that the hydrophobic nature of the amino-terminal por- 
tion of the SAP-1 region contrasts with the hydrophilic nature of the comparable portion of the Pit- 1 and hLEF-1 domains.

To further investigate the selective role of the tyrosine residues, tyrosine- 60 and -67 were mutated to aromatic phenylalanine residues that would not serve as substrates for phosphorylation. These mutants maintained $\sim 90 \%$ wild-type basal transcription activity and full synergy activity with the estrogen receptor (Fig. 5B). These data indicate that tyrosine phosphorylation is not required for the synergy function of Pit-1.

Specific prolactin and growth hormone Pit-1-binding sites dictate differential utilization of the tyrosinespecific synergy domain

In addition to activation of the prolactin gene, Pit-1 also is required for synergistic activation of the growth hormone gene (Ingraham et al. 1988; Ye et al. 1988; Mangalam et al. 1989; Shaufele et al. 1992; Lin et al. 1994). We therefore tested whether synergy between estrogen receptor and Pit-1 would require the same amino-terminal domain when Pit-1 was bound to its recognition element in the growth hormone promoter. To test this possibility, the thyroid hormone response element $(-168$ to $-182 \mathrm{bp})$ of the growth hormone promoter was substituted with the Vit-ERE $\left(\mathrm{GH}_{\text {ERE }}\right)$ (Fig. 6; Glass et al. 1988). Synergistic interactions were observed between Pit- 1 and the estrogen receptor in this context (Fig. 6A), permitting an evaluation of the importance of Pit- 1 domains for the observed synergy events. Removal of the exon 2-encoded domain, or mutation of tyrosine-60 and -67 to alanine (Y60/67A) produced a normal or slightly increased synergy on the growth hormone promoter. These data indicate that in the context of the growth hormone promoter as opposed to the prolactin gene, the exon 2-encoded domain of Pit-1 is not required for synergy with the estrogen receptor. In contrast, deletion of residues $1-44$ produced a clear decrease in synergy. Together, these data indicate that distinct domains of Pit-1 are utilized for synergy in a promoter-dependent manner.

To determine whether this differential utilization of the Pit-1 synergy domain was determined by the nature of the Pit-1-binding sites, the growth hormone-1 (GH-1) Pit-1-binding site was substituted for the prolactin-1D (Prl-1D) Pit-1-binding site in the context of the prolactin 1D-ERE. When the GH-1 Pit-1 site was placed in this context, synergy between Pit-1 and estrogen receptor was observed (Fig. 6B). Analysis of Pit-1 synergy with estrogen receptor revealed that neither the exon-2 encoded domain nor the Y60/67A mutation of Pit-l had any effect. On the 1D-ERE, however, these mutations abolished synergy entirely (Fig. 6B). Therefore, the GH-1 or Prl-1D Pit-1-binding site sequence appears to directly dictate which Pit-1 trans-activation/synergy domain is critical for specific functions.

To begin to define the DNA sequences within each Pit-1-binding site that specify the critical domain required for synergy, we generated chimeric Prl-1D/GH-1 Pit-1 sites. Design of the chimeric site was based on the fact that both contained a core A/TATNCAT motif that permitted alignment of the A/T-rich and flanking $5^{\prime}$ and $3^{\prime}$ sequences. The GH-1 site has two TATNCAT core motifs arranged in a direct repeat orientation that allowed direct swapping of the upstream $5^{\prime}$ or downstream $3^{\prime}$ half-site of GH-1 with the comparable 5' A/T-rich region of the Prl-1D site or the $3^{\prime}$ core motif (AATGCAT). A chimeric element that contained the upstream A/T-rich sequence of the Prl-1D and the downstream TATTCAT core motif of GH-1 resulted in Pit-1 synergy requirements similar to those observed for the prolactin gene and prolactin 1D-ERE reporters (Fig. 6C). Chimeric sites with the GH-1 upstream sequence and the downstream Prl-1D motif exhibited synergy requirements similar to those of the growth hormone promoter and $\mathrm{GH}_{\mathrm{ERE}}$ reporters (Fig. 6C). Therefore, the most critical component of the DNA sequence that dictates the Pit-1 domain-mediating synergy appears to be 9 bp preceding the consensus A/TATNCAT Pit-1 core binding sequence. Sequences 3' to the Prl-1D and GH-1 sites were swapped with no effects (data not shown), indicating that the regions shown in Figure 6 encompass all of the critical regulatory information.

\section{Pit-1 binds to the critical regulatory elements in the growth hormone and prolactin genes as a dimer and monomer, respectively}

In an attempt to further define the mechanism by which these nucleotides in the Pit-l sites specify synergy domain utilization, binding of Pit-1 was re-examined on both the GH-1 and Prl-1D sites. To determine whether Pit-l might exhibit a distinct conformation on the GH-1 and Prl-1D sites, the ABCD binding assay was employed (Glass et al. 1988). Biotinylated oligonucleotides corresponding to the GH-1/ERE, or Prl-1D/ERE elements were used to bind bacterially expressed Pit-1 protein. Bound Pit-1 DNA complexes were isolated using streptavidin-agarose affinity chromatography. Following washing, the DNA-bound Pit-1 was treated for 5, 10, or 15 min with trypsin, and the digested material was analyzed by SDS-PAGE and visualized by silver staining. As shown in Figure 7A, both the sensitivity and the pattern of proteolytic digestion were distinct on each site, suggesting that Pit-1 binds to the Prl-1D DNA site with a different conformation than it assumes on the GH-1 site. Because of these observations, we assessed whether Pit-1 exhibited cooperative binding on the Prl-1D site comparable to that exhibited on the GH-l site (Ingraham et al. 1990). Unexpectedly, the prolactin enhancer Prl-1D site exhibited no cooperative binding of a second Pit-1 protein (Fig. 7B), in contrast to the GH-1 site (Fig. 7B; Ingraham et al. 1990). At very high levels of Pit-1, a second molecule could be forced onto a subset of the Prl-1D AT-rich upstream sites, but with no cooperative binding (data not shown). Thus, Pit-1 bound to the GH-1 site primarily as a dimer and to the Prl-1D site as a monomer. The pattern of binding of Pit-1 to the chimeric recognition elements indicated that cooperativity was determined by the precise AT-rich sequence upstream of 
Holloway et al.

Figure 6. Involvement of the tyrosine-dependent synergy domain in the transcriptional activation of the growth hormone and prolactin genes is dependent on distinct DNA-binding sites. $|A|$ Four expression vectors expressing wild-type Pit-1 (WT), $\Delta 1-44$ Pit-1, $445-72$ Pit-1, or Y60 A/Y67A Pit-1 were cotransfected into CV-1 cells with two reporter plasmids. One reporter contained the Vit-ERE in place of the thyroid hormone response element (TRE) of the growth hormone promoter (GH-ERE). The second reporter was the prolactin enhancer/promoter. Fold synergistic activation by estrogen receptor and Pit-1 is indicated in the absence or presence of $10^{-7} \mathrm{M}$ estrogen. Similar results were obtained in three independent experiments. $(B, C)$ The same Pit- 1 expression plasmids utilized in $A$ were cotransfected with the reporter plasmids GH-1-ERE-P-36 and Prl-1D-ERE-P-36 $(B)$, or GH-1(A)Prl-1D(B)ERE-P-36 and Prl-1D(A) GH-1(B)ERE-P-36 $(C)$, with the estrogen receptor and $10^{-7} \mathrm{M}$ estrogen. Data are expressed in fold synergy over Pit-1 and estrogen receptor in the absence of estrogen.

the A/TATNCAT core motif. Furthermore, the requirement for the tyrosine-dependent synergy domain on these sites correlated with whether Pit-1 bound as a monomer or dimer (Figs. 6 and 7). On the Prl-1D/GH-1 chimeric site, Pit-1 primarily bound as a monomer and required the tyrosine-dependent domain for cooperative synergism with the estrogen receptor. In contrast, on the GH-1/Prl-1D chimeric element, Pit-1 bound primarily as a dimer, and the tyrosine-dependent synergy domain was not required for synergistic interactions with the estrogen receptor.

\section{Discussion}

Short-range synergy events in Pit-1-dependent gene activation

Considerable evidence indicates that Pit-1-dependent function of the prolactin gene distal enhancer, critical for
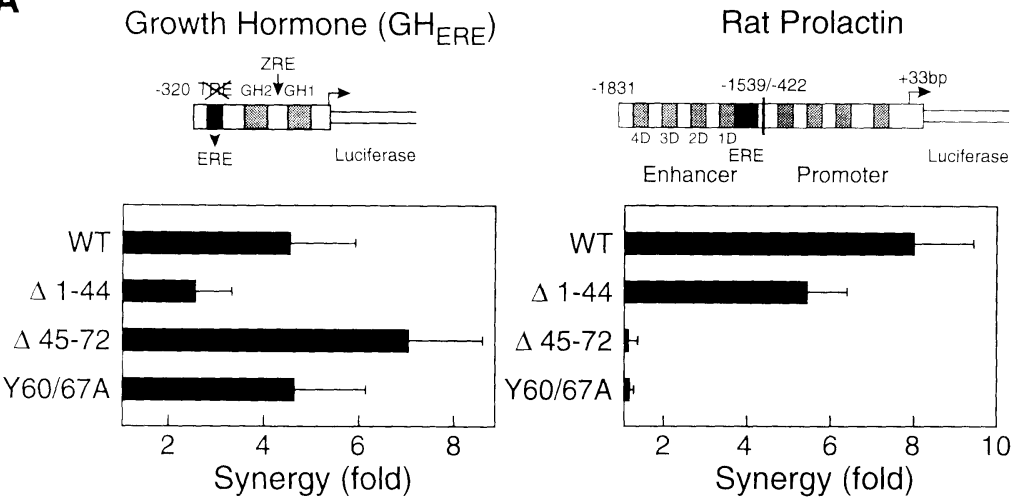

B
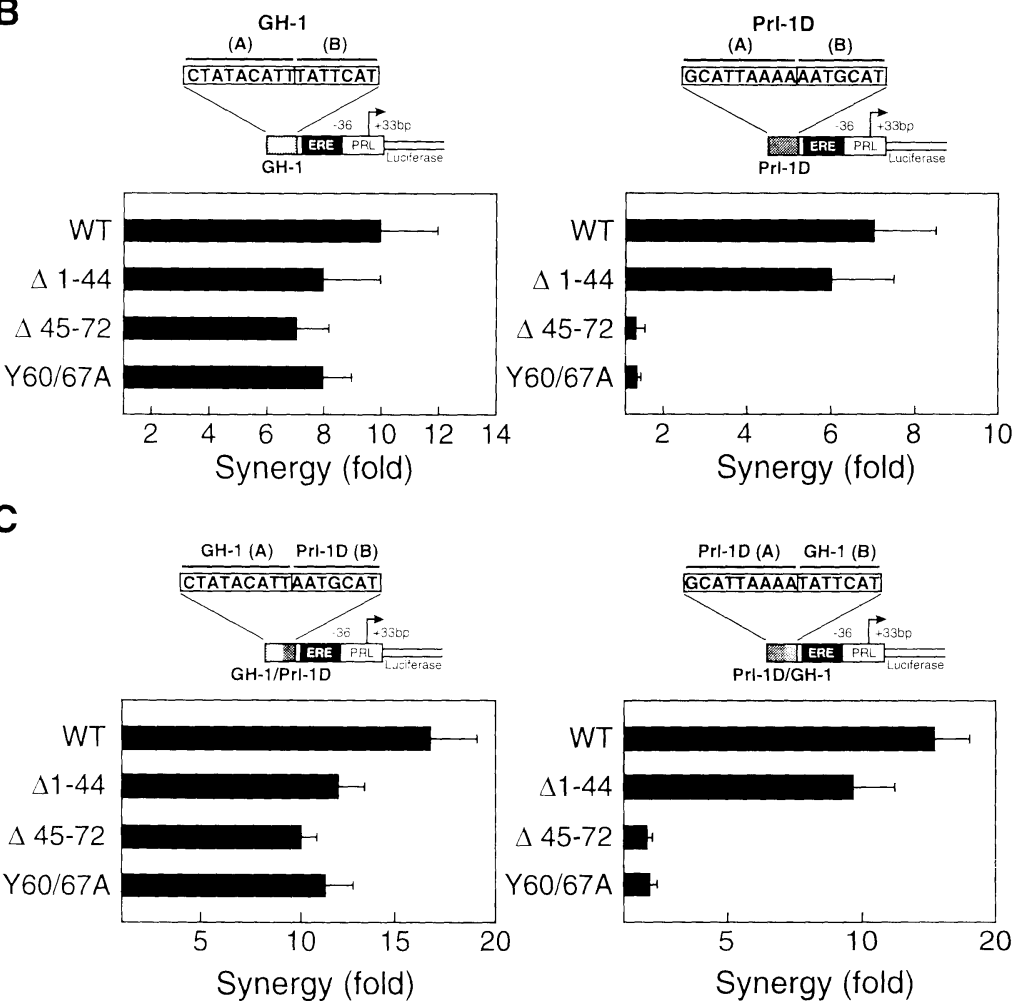

effective expression in vivo, is regulated by activated estrogen receptor (Slabaugh et al. 1982; Somasekhar and Gorski 1988; Crenshaw et al. 1989; Day et al. 1990; Seyfred and Gorski 1990; Simmons et al. 1990). Furthermore, synergistic interactions between Pit-1 and other zinc finger transcription factors appear to be involved in cell type-specific expression of other distal target genes, including the growth hormone gene (Schaufele et al. 1992; Lipkin et al. 1993; Lira et al. 1993; Rhodes et al. 19931. The specific anterior pituitary cell types emerge in a spatially distinct fashion (Simmons et al. 1990), highly reminiscent of the emergence of stripes during Drosophila development. In the case of even-skipped (eve) stripe 2, a specific enhancer has been characterized in which short-range repression of activation function requires binding sites to be within $\sim 50 \mathrm{bp}$ of activator response elements (Small et al. 1991; Gray and Levine 1994), consistent with the model that a local integration 


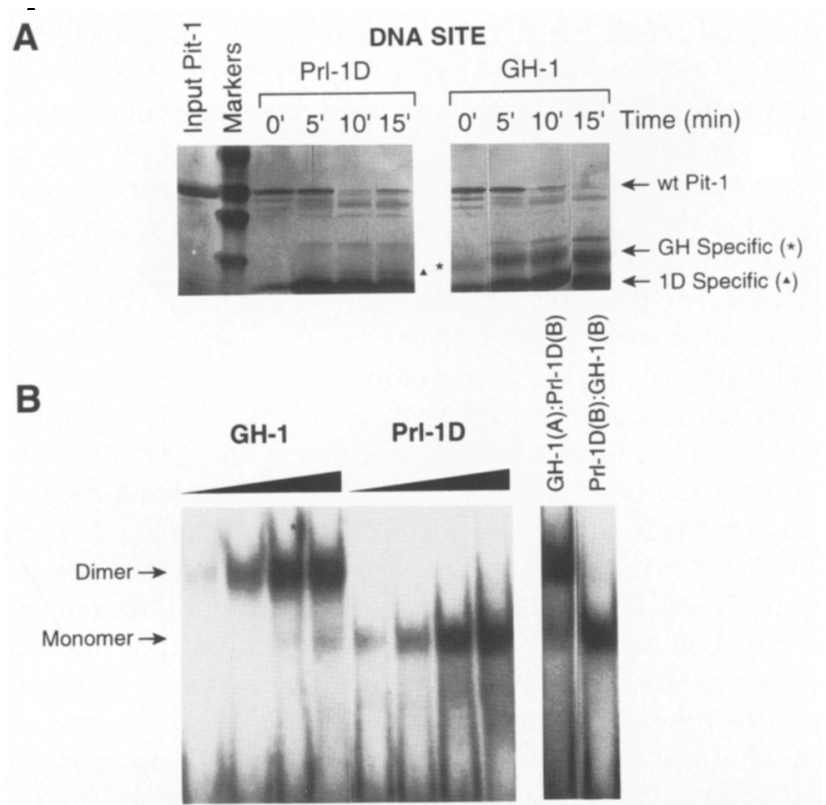

C

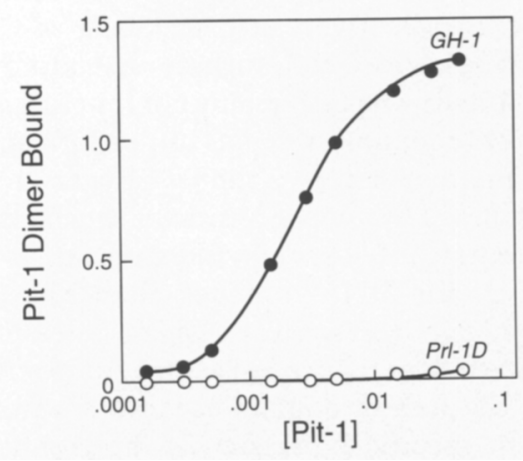

Figure 7. The conformation of Pit-1 is different on the two sites GH-1 and Prl-1D. (A) Utilizing the ABCD-binding assay, Pit-1 protein was bound to the GH-1 or Prl-1D DNA site and treated with the protease trypsin for $0,5,10$, or 15 min following precipitation of DNA-protein complexes. Protease products were separated on $16 \%$ SDS-polyacrylamide gels and visualized with silver stain. Input Pit-1 and protein markers are indicated. Asterisks and arrows indicate GH-1- and Prl-1D-specific protease bands. $(B)$ Mobility gel shift assays with increasing concentrations $(0.0015,0.005,0.015$, and $0.5 \mu \mathrm{g} / \mathrm{ml})$ of Pit- 1 bound to either the GH-1 or Prl-1D Pit-1 DNA-binding sites (lanes $1-4,5-8)$, or Pit-1 $(0.015 \mu \mathrm{g} / \mathrm{ml})$ bound to the compound sites GH-1(A)Prl-1D(B) (lane 9), and Prl-1D(A)GH-1(B) (lane 10). (C) Concentration-dependent binding of Pit-1 dimers to the GH-1 or Prl-1D DNA sites.

of signal leads to repression. Our analysis of the prolactin gene distal enhancer suggests that similar molecular mechanisms may be involved in synergistic activation required to constitute a functional enhancer. In this case, the critical Pit-1 and estrogen receptor DNA sites required for synergistic activation of the prolactin gene distal enhancer do not tolerate spacing of $>50 \mathrm{bp}$, again, consistent with a local integration of signals resulting in synergy. Furthermore, the finding that there are multiple synergy domains in Pit-1 that are differentially utilized in a gene-specific fashion is consistent with the possibility that such short-range positive interactions are mediated by discrete adaptor proteins that discriminate between differentially presented synergy domains.

\section{A gene-specific tyrosine residue-dependent Pit-1 synergy domain}

The initial 72 amino acids of Pit-1 encompass two distinct exon-encoded domains, either of which, in concert with the POU-specific domain, subserve basal trans-activation function. Whereas synergistic interactions between Pit-1 and the estrogen receptor, required for physiologic activation of the prolactin distal enhancer, critically depend on residues $48-72$, this region is not required for synergistic activation of the growth hormone promoter by Pit-1. Interactions between VP16 and SPl activation domains and the specific factors TAF40 and TAF110 have been documented (Gill et al. 1994; Goodrich et al. 1993), and synergism between many classes of transcription factors (e.g., Schüle et al. 1988; Bookbinder et al. 1989; Herbomel 1990; Lin et al. 1990; Lin et al. 1991; Müller et al. 1991; Schaufele et al. 1992; $\mathrm{Du}$ et al. 1993) has been suggested to involve simultaneous contact of one or more components of the core transcriptional machinery (Horikoshi et al. 1991; Lin et al. 1991; Choy and Green 1993; Roberts et al. 1993). However, the mediation of the short-range actions of the tyrosine-dependent synergy domain of Pit-1 is likely to be mediated by a factor that, in essence, integrates the Pit-1 and estrogen receptor actions, consistent with increased estrogen-dependent interactions between the prolactin gene distal enhancer and promoter regions (Cullen et al. 1993).

The exon 2-encoded 25-amino-acid synergy domain of Pit-1, initially noted to be a serine-, proline-, and glycinerich region, has actually proven to be critically dependent on the presence of 2 of the 3 tyrosine residues present within the region. When residues 53-67 of Pit-1 (Y6Y6Y) were replaced with a 13-amino-acid region from the HMG-related hLEF-1 activation domain encompassing the 3 tyrosine residues (amino acids 102-114; Y5Y5Y; Carlsson et al. 1993), a complete maintenance of estrogen-dependent synergy was observed. In contrast, a comparable tyrosine-rich region of SAP-1, which mediates protein activation with the SRF, and noted by Carlsson et al. (1993) to be similar to the hLEF-1 domain, failed to exert any synergistic function. Based on the contrasting ability of tyrosine-containing trans-activation domains present in hLEF-1 and SAP-1 (Waterman and Jones 1990; Waterman et al. 1991; Travis et al. 1991) to function in Pit-1 synergy, it is likely that specific determinants within the domain, in addition to the two critical tyrosine residues, are required for the protein-protein interactions ultimately required for synergy. In part, this might reflect the distinct differences in hydrophilicity between the corresponding region of SAP-1, Pit-1, and hLEF-1. In this regard, the spacing between these two tyrosine residues is not critical, because a Pit-1 protein 
in which the spacing of the tyrosine residues has been altered remains capable of mediating synergy at a level equivalent to the wild-type protein. Because the presence of the two tyrosine residues is not essential for basal activation but is absolutely required for synergistic activation with the estrogen receptor, synergistic activation of the prolactin gene distal enhancer is apparently dependent on a Pit-1 domain not required for effective basal trans-activation. The lack of obvious structural motifs in this domain is consistent with the utilization of proline-rich, glutamine-rich regions and "acidic" trans-activation domains that are, similarly, not likely to be highly ordered (Ptashne 1992; Attardi and Tiian 1993; Goodrich et al. 1993; Gill et al. 1994).

Transcriptional activation by the ligand-binding domain of the estrogen receptor is thought to be mediated by proteins of 140 and $160 \mathrm{kD}$ that bind to a conserved sequence within this domain in a ligand-dependent manner (Halachmi et al. 1994; Tzukerman et al. 1994). A mutation in this conserved sequence that abolishes interaction with P140 and P160 did not abolish the ability of the estrogen receptor to synergize with Pit-1. These observations support the idea that the domain required for short-range synergy with Pit-1 is distinct from that required for ligand-dependent trans-activation on canonical EREs. In the absence of direct cooperative interactions between Pit- 1 and the estrogen receptor, we speculate that an unstructured synergy domain within each transcription factor undergoes an "induced fit" (Frankel and Kim 1991) with adapter proteins, which functions to mediate synergy. In this model, the synergy domains should function as protein-protein interaction interfaces. Consistent with this model, we have recently identified proteins that bind to the Pit-1 amino terminus and also interact with the carboxyl terminus of estrogen receptor in a ligand-dependent fashion. These data are consistent with the notion that the altered synergy domains exert their functions via specific protein-protein interactions. It is tempting to speculate that such interacting factors may serve as adapter proteins to mediate the observed gene-specific synergy events.

Monomer vs. dimer binding on gene-specific DNA response elements dictate Pit-1 synergy domain utilization

Gene-specific utilization of the tyrosine-dependent synergy domain was found to be dictated by the specific sequence to which Pit-1 bound. Exchange of the primary sequence of a 9-bp A/T-rich sequence in the prolactin Pit-1-binding site for that of the growth hormone Pit-1binding site results in "switching" of the exon-2 domain dependence critical for prolactin synergy to a pattern more characteristic of the growth hormone gene function. DNA site-specific determination of synergy domain utilization appears to be dictated by whether Pit-1 binds as a monomer or dimer to the critical regulatory DNA element. The principle that DNA sites modulate the conformation of transcription factors appears to apply for many classes of factors, including nuclear recep- tors and NFk $\beta$ (e.g., Fujita et al. 1992; Thanos and Maniatis 1992; Kurokawa et al. 1993; Perlmann et al. 1993). The example of Pit-1 and estrogen receptor synergy provides the first example of DNA site specification of synergy domain use based on monomer versus dimer binding. On the Prl-1D site, to which Pit-1 binds as a monomer, the exon-2 encoded tyrosine-dependent synergy domain constitutes the critical region for synergistic gene activation events with the estrogen receptor. In contrast, this region is not required for synergy with the estrogen receptor on DNA sites such as $\mathrm{GH}-1$, to which Pit-1 binds cooperatively as a dimer. Our data are most compatible with a model in which the tyrosine-dependent domain on the GH-1 DNA site is no longer configured in a fashion that permits the protein-protein interactions critical for synergistic activation. Differential control by monomer versus dimer configurations may be a strategy used widely for both positive and negative control of gene expression. Positive versus negative control of gene transcription by Krüppel has been postulated to reflect the selective actions of monomers and dimers, respectively. In this case, amino- or carboxy-terminal regions of Krüppel are selectively utilized (Sauer and Jäckle 1993). Our findings with Pit-1 suggest that alternative use of synergy domains represent another functional outcome of binding of monomers versus dimers of a specific factor. Furthermore, whereas Krüppel effects are suggested to be regulated by concentration of this factor, we find that differential Pit-1 synergy domain use is regulated by gene-specific DNA response elements. These data, directly linking gene-specific response elements to alternative synergy domain use, raise intriguing possibilities regarding the role of domain-specific adapter proteins in cell type-specific expression of the growth hormone and prolactin genes. These events are likely to be prototypic for many synergistic interactions among diverse classes of transcription factors.

\section{Materials and methods}

Plasmid construction

Luciferase reporters Wild-type rat prolactin enhancer and promoter luciferase reporters were described previously (Waterman et al. 1988). Site-directed mutagenesis was used to construct mutant prolactin reporters. Seven base pairs of either the ERE or individual Pit-1-binding sites were replaced with a BstE2 restriction enzyme recognition site. Oligonucleotides used for mutagenesis were as follows: ERE-Mut, 5'-CAAAGCACTCTGGTTACCAGTGACAAAAATG-3'; 1D-Mut, 5'-GACATAGTGACAAAAGGTTACCTTTTAATGCACTCC-3'; 2D-Mut, CTCATGTTTTAGAGAGGTTACCAATGATGTCATTATG-3'; 3D-Mut, 5'-AATGATGTCATTATGGGTTACCATAATGAAGTTGCTG-3'; 4D-Mut, 5'-TTTAATTTCGGGATTGGTTACCCTGAAGCAGCTTG-3'. For P460s, 4P, 3P, and 2P Pit-1-binding sites were replaced with BstE2 sites in the context of $1 \mathrm{P}$-Mut as described (Mangalam et al. 1989). Oligonucletides used for this mutagenesis were as follows: 4P-Mut, 5'-TTTGCTGTAATTAGGTTACCTCCTTCCTTT-3'; 3P-Mut, 5'-CTTCCTGA-ATGGTTACCAGAAATAAAATAC-3'; and 2P-Mut, 5'-AAA- TACCATTTGCCATTGGAAATTATTGGG-3'. Vit-ERE was con- 
structed by replacing the prolactin ERE palindrome $(-1567$ to -1583 ) with a consensus palindromic Vit-ERE (AGGTCACAGTGACCT). 1D-ERE-P460D was constructed by annealing, filling, and ligating the following oligonucleotides into the filled XhoI site of P460A: 5'-GATCCGCATTAAAAAATGCATTTTTGTCACTATGTCCTAGAGTGCTTTGGGGTCAGAAA-3' and 5'-GATCTTTCTGACCCCAAAGCACTCTAGGACATAGTGACAAAAATGCATTTTTTAATCGG-3'. Ligation of these same oligonucleotides into the BamHI site of the P-36 luciferase reporter plasmid (Ingraham et al. 1988) generated the 1D-ERE-P-36 construct. Similarly, ligation of the following oligonucletides into BamHI site of P-36 yielded 1D- +6-EREP-36, 5'-GATCTCGCATTAAAAAATGCATTTTTGTGGATCCTGTCACTATGTCCTAGAGTGCTTTGGGGTCAGAAA-3' and 5' GATCTTTCTGACCCCAAAGCACTCTAGGACATAGTGACAGGATCCACAAAAATGCATTTTTTAATGCGA-3'; and 1D-+7-ERE-P-36, 5'-GATCCGCATTAAAAAATGCAT TTTTGTGGTTACCTGTCACTATGTCCTAGAGTOGOTT TGGGGTCAGAAA- ${ }^{\prime}$ ' and 5'-GATCTTTCTGACCCCAAAGCACTCTAGGACATAGTGACAGGTAACCACAAAAATGCATTTTTTAATGCG-3'. 1D- + 54-ERE-P-36 was constructed was constructed by ligation of the following annealed oligonucleotides into the BamHI site of 1D-ERE- +6-P-36: 5'-GATCCCTCAATCAAAGTCTGTTCTCTATTTCAAAGGAGCATCTTGAGTGCAGA-3' and 5'-GATCTTTCTGACCCCAAAGCACTCTAGGACATAGTGACAAGTACTGTATGTACATACAGTACG-3'.

The 2X-Lex-P-36 luciferase reporter was constructed by annealing and ligating the following oligonucleotides into the BamHI site of P-36: 5'-GATCCACTGGCGTACTGTATGTACATACAGTACTATCAGA-3' and 5'-GATCTCTGATAGTACTGTATGTACATACAGTACGCCAGTG-3'.

GH- ${ }_{\text {(ERE) }}$ was as described (Glass et al. 1988). Additional oligonucleotides were annealed and ligated into the BamHI site of P-36 to generate the following constructs: GH-1-ERE-P-36, 5'-GATCCCTATACATTTATTCATGGCTGTCACTATGTCCTAGAGTGCTTTGGGGTCAGAAA-3' and 5'-GATCTTTCTGACCCCAAAGCACTCTAGGACATAGTGACAGCCATGAATAAATGTATAGG-3'; Prl-1D-ERE-P-36, 5'-GATCCGCATTAAAAAATGCATTTTTGTCACTATGTCCTAGAGTGCTTTGGGGTCAGAAA-3' and 5'-GATCTTTCTGACCCCAAAGCACTCTAGGACATAGTGACAAAAATGCATTTTTTAATGCG-3'; GH-1(A)/Prl-1D(B)-ERE-P-36, 5'-GATCCCTATACATTAATGCATTTTTGTCACTATGTCCTAGAGT GCTTTG-GGGTCAGAAA-3' and 3'-GATCTTTCTGACCCCAAAGCACTCTAGGACATAGTGCAAAAATGCATTAATGTATA-GG-3'; Prl-1D(A)GH-1(B)-ERE-P-36, 5'-GATCCGCATTAAAATATTCATTTTTGTCACTATGTCCTAGAGTGCTTTGGGGTCAGAAA-3' and 5'-GATCTTTCTGACCCCAAAGCACTCTAGGACATAGTGACAAAAATGAATATTTTAATGCG-3'.

Expression vectors The following plasmid constructs were as described previously: Rous sarcoma virus (RSV)-ER (Adler et al. 1988); RVS-neomycin resistance (Holloway et al. 1990); cytomegalovirus (CMV)-Pit-1 $\Delta 8-128$, CMV-Lex, CMV-Lex/Pit-1, and CMV-Lex/Oct2 (Ingraham et al. 1988); and CMV-Pit-1 $\Delta 1-$ 26 (Voss et al. 1991). CMV-Pit-1 $\Delta 1-44$ and CMV-Pit-1 $\Delta 45-72$ were generated by loop-out mutagenesis. Site-directed mutagenesis was employed to introduce nucleotide changes in Pit-1 codons as follows: TAC Y53A GCA; TAT Y60A GCC; TAT Y60F TTT; GGA G61Y TAC; AAC N62A GCT; AAC N62D GAT; TCC S65A GCC; CAG Q63A GCG; CAG Q63E GAG; CAG Q63Y TAC; ACC T66A GCC; TAT Y67A GCG; TAT Y76A TTC; and TAT Y67N AAC.

\section{Transient cotransfection assays}

Cotransfection assays were performed as described (Holloway et al. 1990). Briefly, $3 \mu \mathrm{g}$ of reporter plasmid (or $2 \mu \mathrm{g}$, where noted), and $1 \mu \mathrm{g}$ of each effector plasmid was cotransfected (except where noted) into CV-1 African green monkey kidney cells plated at a density of $9 \times 10^{5} /$ cell per $60-\mathrm{mm}$ plate, using the method of Chen and Okayama (1987). Hormone was added at the time of transfection and again $24 \mathrm{hr}$ later at a final concentration of $10^{-7} \mathrm{M}$. Cells were harvested $48 \mathrm{hr}$ after transfection and luciferase activity was assayed as described previously (Holloway et al. 1990). Transfected cell nuclear extracts were prepared utilizing methods described previously (Holloway et al. 1990).

\section{$A B C D$-binding assay}

The ABCD-binding assay was performed as described (Glass et al. 1988). The 1D-ERE region was produced by annealing the oligonucleotides 5'-AAGGGGATCCGCATTAAAAAATGCATTTTTGTCACTATGTCCTAGAGTGCTTTGGGGTCAGAA-3' and 5'-AGGAAGATCTTTCTGACCCCAAAGCACTCTAGGACATAGTGACAAAAATGCATTTTTTAATGC-3'. The overhangs of annealed oligonucleotides were filled using Klenow enzyme in the presence of biotin-11-dUTP to form the biotinylated ID-ERE DNA element. Assays utilized 100 fmoles of the biotinylated 1D-ERE DNA element and baculovirus-produced estrogen receptor, which was the generous gift of Dr. Myles Brown (Harvard Medical School, Boston, MA).

\section{Mobility gel shift assay}

The double-stranded oligonucleotides 1D-ERE, GH-1-ERE, GH-1/A)Prl-1D(B)-ERE, and Prl-1D(A)GH-1/B)-ERE were radiolabeled with $\left[\alpha^{-32} \mathrm{P} \mid \mathrm{ATP}\right.$ utilizing polynucleotide kinase. Assays were performed as outlined (Drolet et al. 1991), except where noted in the figure legends. In vitro-translated radiolabeled and nonradiolabeled estrogen receptor and Pit-1 were produced utilizing the Promega TNT transcription/translation system.

\section{$A B C D$ protease assay}

To perform protease digestions of Pit- 1 bound to DNA; doublestranded DNA sites were prepared from oligonucleotides containing a 5'-biotinylated residue. Bacterially produced Pit-1 protein $(5 \mu \mathrm{g})$ was incubated with $3 \mu \mathrm{g}$ of biotinylated DNA for $20-30 \mathrm{~min}$ at $25^{\circ} \mathrm{C}$. DNA complexes were isolated as described (Glass et al. 1988). Protease digestion was performed on the recovered Pit-1/DNA complexes. At the end of the last buffer $\mathrm{H}$ wash, 5 units of trypsin (Boehringer Mannheim) was added directly to the Pit-1/DNA complexes, and the mixture was incubated at room temperature for time periods as indicated $(0,5,10$, and $20 \mathrm{~min}$ ). Equal volumes of $2 \times$ protein sample buffer were added to stop the digestions, and the samples were heated at $95^{\circ} \mathrm{C}$ for $5 \mathrm{~min}$. After a brief centrifugation, the digested samples were resolved on SDS-polyacrylamide gels and visualized by silver staining (Bio-Rad).

\section{Acknowledgments}

The contributions of Jeffrey Holloway and Daniel Szeto to this work are to be considered equivalent. We acknowledge the valuable contributions and reagents provided by Charles Nelson, Stuart Adler, Holly Ingraham, and Victor Yu. We thank Donald McDonnell for generously providing the ER mutants and Myles Brown for baculovirus-expressed ER. The comments and sug- 
gestions of Aimee Ryan, Thorsten Heinzel, Simon Rhodes, Bogi Andersen, Gabriel DiMattia, and Susan Martin during the preparation of this paper are greatly appreciated. M.G.R. is an investigator with the Howard Hughes Medical Institute. This work was supported by a grant from the National Institutes of Health (DK18477).

The publication costs of this article were defrayed in part by payment of page charges. This article must therefore be hereby marked "advertisement" in accordance with 18 USC section 1734 solely to indicate this fact.

\section{References}

Adler, S., M.L. Waterman, X. He, and M.G. Rosenfeld. 1988. Steroid receptor-mediated inhibition of rat prolactin gene expression does not require the receptor DNA-binding domain. Cell 52: 685-695.

Andersen, B. and M.G. Rosenfeld. 1994. Pit-1 determines cell types during development of the anterior pituitary gland. $J$. Biol. Chem. 269: 29335-29338.

Attardi, L.D. and R. Tjian. 1993. Drosophila tissue-specific transcription factor NTF-1 contains a novel isoleucine-rich activation motif. Genes \& Dev. 7: 1341-1353.

Baniahmad, C., M. Muller, J. Altschmied, and R. Renkawitz. 1991. Co-operative binding of the glucocorticoid receptor DNA binding domain is one of at least two mechanisms for synergism. J. Mol. Biol. 222: 155-165.

Bookbinder, L., V.J. Miralles, and D. Reinberg. 1989. TPA can overcome the requirement for EIA and together act synergistically in stimulating expression of the adenovirus EIII promoter. EMBO I. 8: 4239-4250.

Cao Z., E.A. Barron, and Z.D. Sharp. 1988. Prolactin upstream factor 1 mediates cell-specific transcription. Mol. Cell. Biol. 8: $5432-5438$.

Carey M., Y.S. Lin, M.R. Green, and M. Ptashne. 1990. A mechanism for synergistic activation of a mammalian gene by GAL4 derivatives. Nature 345: 361-364.

Carlsson, P., M.L. Waterman, and K.A. Jones. 1993. The hLEF/ TCF-1 $\alpha$ HMG protein contains a context-dependent transcriptional activation domain that induces the TCR $\alpha$ enhancer in T cells. Genes \& Dev. 7: 2418-2430.

Chen, C. and H. Okayama. 1987. High efficiency transformation of mammalian cells by plasmid DNA. Mol. Cell. Biol. 7: 2745-2752.

Choy, B. and M.R. Green. 1993. Eukaryotic activators function during multiple steps of preinitiation complex assembly. Nature 366: 531-533.

Crenshaw, E.B. III, K. Kalla, D.M. Simmons, L.W. Swanson, and M.G. Rosenfeld. 1989. Cell-specific expression of the prolactin gene in transgenic mice is controlled by synergistic interactions between promoter and enhancer elements. Genes \& Dev. 3: 959-972.

Cullen, K.E., M.P. Kladde, and M.A. Seyfred. 1993. Interaction between transcription regulatory regions of prolactin chromatin. Science 261: 203-206.

Dalton, S. and R. Treisman. 1992. Characterization of SAP-1, a protein recruited by serum response factor to the $\mathrm{c}$-fos serum response element. Cell 68: 597-612.

Day, R.N. and R.A. Maurer. 1989. The distal enhancer region of the rat prolactin gene contains elements conferring response to multiple hormones. Mol. Endocrinol. 3: 3-9.

Day, R.N., S. Koike, M. Sakai, M. Muramatsu, and R.A. Maurer. 1990. Both Pit-1 and the estrogen receptor are required for estrogen responsiveness of the rat prolactin gene. Mol. Endocrinol. 12: 1964-1971.

Drolet D.W., K.M. Scully, D.M. Simmons, M. Wegner, K.T.
Chu, L.W. Swanson, and M.G. Rosenfeld. 1991. TEF, a transcription factor expressed specifically in the anterior pituitary during embryogenesis, defines a new class of leucine zipper proteins. Genes \& Dev. 5: 1739-1753.

Du, W., D. Thanos, and T. Maniatis. 1993. Mechanisms of transcriptional synergism between distinct virus-inducible enhancer elements. Cell 74: 887-898.

Fawell, S.E., J.A. Lees, R. White, and M.G. Parker. 1990. Characterization and colocalization of steroid binding and dimerization activities in the mouse estrogen receptor. Cell 60: $953-962$.

Frankel, A.D. and P.S. Kim. 1991. Modular structure of transcription factors: Implications for gene regulation. Cell 65: 717-719.

Fujita, T., G.P. Nolan, S. Ghosh, and D. Baltimore. 1992. Independent modes of transcriptional activation by the p50 and p65 subunits of NF-kB. Genes \& Dev. 6: 775-787.

Garnier, J. 1978. Analysis of the accuracy and implications of simple methods for predicting the secondary structure of globular proteins. J. Mol. Biol. 120: 97-120.

Giese, K. and R. Grosschedl. 1993. LEF-1 contains an activation domain that stimulates transcription only in a specific context of factor-binding sites. EMBO J. 12: 4667-4676.

Gill, G., E. Pascal, Z.H. Tseng, and R. Tjian. 1994. A glutaminerich hydrophobic patch in transcription factor Spl contacts the dTAFIIl 10 component of the Drosophila TFIID complex and mediates transcriptional activation. Proc. Natl. Acad. Sci. 91: 192-196.

Glass, C.K., J.M. Holloway, O.V. Devary, and M.G. Rosenfeld. 1988. The thyroid hormone receptor binds with opposite transcriptional effects to a common sequence motif in thyroid hormone and estrogen response elements. Cell 54: 313323.

Godfrey, P., I.O. Rahal, W.G. Beamer, N.G. Copeland, N.A. Jenkins, and K.E. Mayo. 1993. GHRH receptor of little mice contains a missense mutation in the extracellular domain that disrupts receptor function. Nature Genet. 4: 227-232.

Goodrich, J.A., T. Hoey, C.J. Thut, A. Admon, and R. Tjian. 1993. Drosophila TAFII40 interacts with both a VP16 activation domain and the basal transcription factor TFIIB. Cell 75: 519-530.

Gray, S., P. Szymanski, and M. Levine. 1994. Short-range repression permits multiple enhancers to function autonomously within a complex promoter. Genes \& Dev. 8: 1829-1838.

Gutierrez-Hartman, A., S. Siddiqui, and S. Loukin. 1987. Selective transcripiton and DNase 1 protection of the rat prolactin gene by $\mathrm{GH}_{3}$ pituitary cell-free extracts. Proc. Natl. Acad. Sci. 84: 5211-5215.

Halachmi, S., E. Marden, G. Martin, H. MacKay, C. Abbondanza, and M. Brown. 1994. Estrogen receptor-associated proteins: Possible mediators of hormone-induced transcription. Science 264: 1455-1457.

Herbomel, P. 1990. Synergistic activation of eukaryotic transcription: The multiacceptor target hypothesis. New Biol. 2: 1063-1070.

Hershlag, D. and E.B. Johnson. 1993. Synergism in transcriptional activation: A kinetic view. Genes \& Dev. 7: 173-179.

Holloway, J.M., C.K. Glass, S. Adler, C.A. Nelson, and M.G. Rosenfeld. 1990. The C-terminal interaction domain of the thyroid hormone receptor confers the ability of the DNA site to dictate positive or negative transcriptional activity. Proc. Natl. Acad. Sci. 87: 8160-8164.

Horikoshi, N., K. Maguire, A. Kralli, E. Maldonado, D. Reinberg, and R. Weinmann. 1991. Direct interaction between adenovirus E1A protein and the TATA box binding transcription factor IID. Proc. Natl. Acad. Sci. 88: 5124-5128. 
Ingraham, H.A., R. Chen, H.J. Mangalam, H.P. Elsholtz, S.E. Flynn, C.R. Lin, D.M. Simmons, L. Swanson, and M.G. Rosenfeld. 1988. A tissue-specific transcription factor containing a homeodomain specifies a pituitary phenotype. Cell 55: 519-529.

Ingraham, H.A., S.E. Flynn, J.M. Voss, V.R. Albert, M.S. Kapiloff, L. Wilson, and M.G. Rosenfeld. 1990. The POU-specific domain of Pit-1 is essential for sequence-specific, high affinity DNA binding and DNA-dependent Pit-1-Pit-1 interactions. Cell 61: 1021-1033.

Kim, K.E., R.N. Day, and R.A. Maurer. 1989. Functional analysis of the interaction of a tissue-specific factor with an upstream enhancer element of the rat prolactin gene. Mol. Endocrinol. 2: 1374-1381.

Kumar, V., S. Green, G. Stack, M. Berry, J.R. Jin, and P. Chambon. 1987. Functional domains of the human estrogen receptor. Cell 51: 941-951.

Kurokawa, R., V.C. Yu, A. Naar, S. Kyakumoto, Z. Han, S. Silverman, M.G. Rosenfeld, and C.K. Glass. 1993. Differential orientations of the DNA-binding domain and carboxy-terminal dimerization interface regulate binding site selection by nuclear receptor heterodimers. Genes \& Dev. 7: 1423-1435.

Lees, J.A., S.E. Fawell, and M.G. Parker. 1989. Identification of two transactivation domains in the mouse estrogen receptor. Nucleic Acids Res. 17: 5477-5488.

Li, S., E.B. Crenshaw III, E.J. Rawson, D.M. Simmons, L.W. Swanson, and M.G. Rosenfeld. 1990. Dwarf locus mutants lacking three pituitary cell types result from mutations in the POU-domain gene Pit-1. Nature 347: 528-533.

Lin, C.R., S.-C. Lin, C.P. Chang, and M.G. Rosenfeld. 1992. Pit-1-dependent expression of the receptor for growth hormone releasing factor mediates pituitary cell growth. Nature 360: 765-768.

Lin, S.-C., C.R. Lin, I. Gukovsky, A.J. Lusis, P.E. Sawchenko, and M.G. Rosenfeld, 1993. Molecular basis of the little mouse phenotype and implications for cell type-specific growth. Nature 364: 208-213.

Lin, S.-C., S. Li, D.W. Drolet, and M.G. Rosenfeld. 1994. Pituitary ontogeny of the Snell dwarf mouse reveals Pit-1-independent and Pit-1-dependent origins of the thyrotrope. Development 120: 515-522.

Lin, Y.S., M. Carey, M. Ptashne, and M.R. Green. 1990. How different eukaryotic transcriptional activators can cooperate promiscuously. Nature 345: 359-361.

Lin, Y.S., I. Ha, E. Maldonado, D. Reinberg, and M.R. Green. 1991. Binding of general transcription factor TFIIB to an acidic activating region. Nature 353: 569-571.

Lipkin, S.M., A.M. Näär, K.A. Kalla, R.A. Sack, and M.G. Rosenfeld. 1993. Identification of a novel zinc finger protein binding a conserved element critical for Pit-1-dependent growth hormone gene expression. Genes \& Dev. 7: 1674-1687.

Lira, S.A., K.A. Kalla, C.K. Glass, D.W. Drolet, and M.G. Rosenfeld. 1993. Synergistic interactions between Pit-1 and other elements are required for effective somatotroph rat growth hormone gene expression in transgenic mice. Mol. Endocrinol. 7: 694-701.

Mangalam, H.J., V.R. Albert, H.A. Ingraham, M. Kapiloff, L. Wilson, C. Nelson, H. Elsholtz, and M.G. Rosenfeld. 1989. A pituitary POU domain protein, Pit-1, activates both growth hormone and prolactin promoters transcriptionally. Genes \& Dev. 3: 946-958.

Martinez, E., Y. Dusserre, W. Wahli, and N. Mermod. 1991. Synergistic transcriptional activation by CTF/NF-I and the estrogen receptor involves stabilized interactions with a limiting target factor. Mol. Cell. Biol. 11: 2937-2945.

Maurer, R.A. and A.C. Notides. 1987. Identification of an estro- gen response element from the 5' flanking region of the rat prolactin gene. Mol. Cell. Biol. 7: 4247-4254.

Müller, M., C. Baniahmad, C. Kaltschmidt, and R. Renkawitz. 1991. Multiple domains of the glucocorticoid receptor involved in synergism with the CACCC box factor(s). Mol. Endocrinol. 5: 1498-1503.

Nelson, C., E.B. Crenshaw III, R. Franco, S.A. Lira, R.M. Evans, and M.G. Rosenfeld. 1986. Discrete cis-active genomic sequences dictate the pituitary cell type-specific expression of the rat prolactin growth hormone gene. Nature 322: 557562.

Nelson, C., V.R. Albert, H.P. Elsholtz, L.I.-W. Lu, and M.G. Rosenfeld. 1988. Activation of cell-specific expression of rat growth hormone and prolactin genes by a common transcription factor. Science 239: 1400-1405.

Nowakowski, B.E. and R.A. Maurer. 1994. Multiple Pit-1 binding sites facilitate estrogen responsiveness of the prolactin gene. Mol. Endocrinol. 8: 1742-1749.

Perlmann, T., P.N. Rangarajan, K. Umesono, and R.M. Evans. 1993. Determinants for selective RAR and TR recognition of direct repeat HREs. Genes \& Dev. 7: 1411-1422.

Peterson, C.L. and I. Herskowitz. 1992. Characterization of the yeast SWI1, SWI2, and SWI3 genes, which encode a global activator of transcription. Cell 68: 573-583.

Ptashne, M. 1992. A genetic switch, 2nd ed. Blackwell Scientific Publications, Cambridge, MA.

Rhodes, S.J., R. Chen, G.E. DiMattia, K.M. Scully, K.A. Kalla, S.-C. Lin, V.C. Yu, and M.G. Rosenfeld. 1993. A tissue-specific enhancer confers Pit-1-dependent morphogen inducibility and autoregulation on the pit-1 gene. Genes \& Dev. 7: 913-932.

Roberts, S.G., I. Ha, E. Maldonado, D. Reinberg, and M.R. Green. 1993. Interaction between an acidic activator and transcription factor TFIIB is required for transcriptional activation. Nature 363: 741-744.

Sauer, F. and J. Jäckle. 1993. Dimerization and the control of transcription by Kruppel. Nature 364: 454-457.

Schaufele, F., B.L. West, and J.D. Baxter. 1992. Synergistic activation of the rat growth hormone promoter by Pit-1 and the thyroid hormone receptor. Mol. Endocrinol. 6: 656-665.

Schüle, R., M. Muller, C. Kaltschmidt, and R. Renkawitz. 1988. Many transcription factors interact synergistically with steroid receptors. Science 242: 1418-1421.

Seyfred, M.A. and J. Gorski. 1990. An interaction between 5' flanking distal and proximal regulatory domains of the rat prolactin gene is required for transcriptional activation by estrogens. Mol. Endocrinol. 4: 1226-1234.

Simmons, D.M., J.W. Voss, H.A. Ingraham, J.M. Holloway, R.S. Broide, M.G. Rosenfeld, and L.W. Swanson. 1990. Pituitary cell phenotype involves cell-specific Pit-1 mRNA translation and synergistic interactions with other classes of transcription factors. Genes \& Dev. 4: 695-711.

Slabaugh, M.D., M.E. Lieberman, J.J. Rutledge, and J. Gorski. 1982. Ontogeny of growth hormone and prolactin gene expression in mice. Endocrinology 110: 1489-1497.

Small, S., R. Kraut, T. Hoey, R. Warrior, and M. Levine. 1991. Transcriptional regulation of a pair-rule stripe in Drosophila. Genes \& Dev. 5: 827-839.

Somasekhar, M.B. and J. Gorski. 1988. Two elements of the rat prolactin 5 ' flanking region are required for its regulation by estrogen and glucocorticoids. Gene 69: 13-21.

Strähle, U., W. Schmid, and G. Schutz. 1988. Synergistic action of the glucocorticoid receptor with transcription factors. EMBO I. 7: 3389-3395.

Tasset, D., L. Tora, C. Fromental, E. Scheer, and P. Chambon. 1990. Distinct classes of transcriptional activating domains 


\section{Holloway et al.}

function by different mechanisms. Cell 61: 1177-1187.

Thanos, D. and T. Maniatis. 1992. The high mobility group protein HMG $\mathrm{I}(\mathrm{Y})$ is required for NF-kappa B-dependent virus induction of the human IFN-beta gene. Cell 71: 777-789.

Tora, L., J. White, C. Brou, D. Tasset, N. Webster, E. Scheer, and P. Chambon. 1989. The human estrogen receptor has two independent nonacidic transcriptional activation functions. Cell 59: 477-487.

Travis, A., A. Amsterdam, C. Belanger, and R. Grosschedl. 1991. LEF-1, a gene encoding a lymphoid-specific protein with an HMG domain regulates $T$-cell receptor alpha enhancer function. Genes \& Dev. 5: 880-894.

Treisman, R., R. Marais, and J. Wunne. 1992. Spatial flexibility in ternary complexes between SRF and its accessory proteins. EMBO J. 11: 4631-4640.

Tzukerman, M.T., A. Esty, D. Santiso-Mere, P. Danielian, M.G. Parker, R.B. Stein, J.W. Pike, and D.P. McDonnell. 1994. Human estrogen receptor transactivational capacity is determined by both cellular and promoter context and mediated by two functionally distinct intramolecular regions. Mol. Endocrinol. 8: 21-30.

van Genderen, C., R.M. Okamura, I. Farinas, R.G. Quo, T.G. Parslow, L. Bruhn, and R. Grosschedl. 1994. Development of several organs that require inductive epithelial-mesenchymal interactions is impaired in LEF-1-deficient mice. Genes \& Dev. 8: 2691-2703.

Voss, J.W., T.P. Yao, and M.G. Rosenfeld. 1991. Alternative translation initiation site usage results in two structurally distinct forms of Pit-1. J. Biol. Chem. 266: 12832-12835.

Waterman, M.L., S.R. Adler, C.A. Nelson, G.L. Greene, R.M. Evans, and M.G. Rosenfeld. 1988. A single domain of the estrogen receptor confers DNA binding and transcriptional activation of the rat prolactin gene. Mol. Endocrinol. 2: 14 21.

Waterman, M. and K.A. Jones. 1990. Purification of TCF-1 $\alpha$, a T-cell-specific transcription factor that activates the T-cell receptor $\mathrm{C} \alpha$ gene enhancer in a context-dependent manner. New Biol. 2: 621-636.

Waterman, M.L., W.H. Fischer, and K.A. Jones. 1991. A thymusspecific member of the HMG protein family regulates the human $\mathrm{T}$ cell receptor $\mathrm{C}$ alpha enhancer. Genes \& Dev. 5: 656-669.

Ye, Z.-S., B.M. Forman, A. Aranda, A. Pascual, H.-Y. Park, J. Casanova, and H.H. Samuels. 1988. Rat growth hormone gene expression: Both cell-specific and thyroid hormone response elements are required for thyroid hormone regulation. I. Biol. Chem. 263: 7821-7829. 


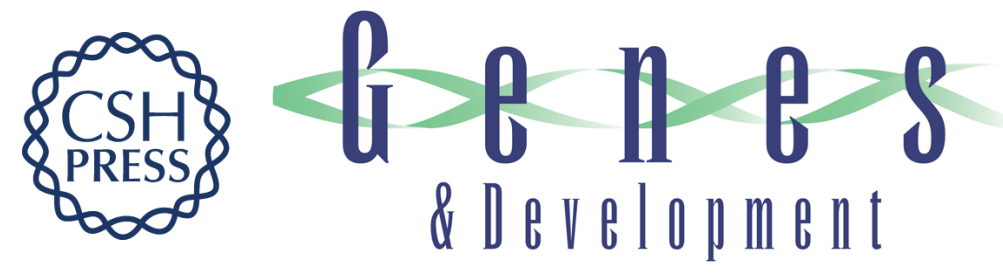

\section{Pit-1 binding to specific DNA sites as a monomer or dimer determines gene-specific use of a tyrosine-dependent synergy domain.}

J M Holloway, D P Szeto, K M Scully, et al.

Genes Dev. 1995, 9:

Access the most recent version at doi:10.1101/gad.9.16.1992

References This article cites 79 articles, 33 of which can be accessed free at:

http://genesdev.cshlp.org/content/9/16/1992.full.html\#ref-list-1

License

Email Alerting Receive free email alerts when new articles cite this article - sign up in the box at the top Service right corner of the article or click here.

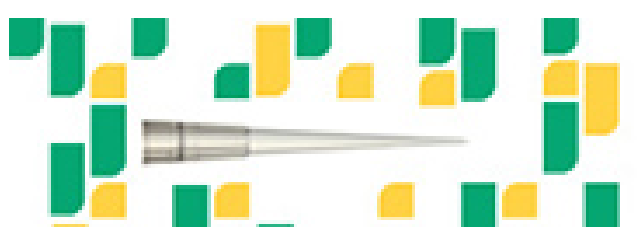

Focused on your science. 